\title{
Expression of MMP-1, -2, and -8 in longissimus dorsi muscle and their relationship with meat quality traits in cattle
}

\author{
Y.X. Qi, X.H. Zhang, Y.Q. Wang, Y.Z. Pang, Z.B. Zhang, T.L. Zhang and \\ Z.X. Zhang \\ College of Animal Science, Henan University of Science and Technology, Luoyang, \\ He'nan, China \\ Corresponding author: X.H. Zhang \\ E-mail: zhangxiaohui78@126.com \\ Genet. Mol. Res. 15 (1): gmr.15017593 \\ Received September 9, 2015 \\ Accepted December 4, 2015 \\ Published March 4, 2016 \\ DOI http://dx.doi.org/10.4238/gmr.15017593
}

ABSTRACT. The extracellular matrix (ECM) is the major macromolecule in skeletal muscle, which affects meat quality greatly. The remodeling of the ECM is mainly regulated by matrix metalloproteinases (MMPs). The expression patterns of MMP-1, -2 , and -8 in longissimus dorsi muscle were explored using quantitative real-time polymerase chain reaction. The results show that the expression of MMP-1, -2 , and -8 decreased significantly from 135 days of pregnancy to postnatal 30 months. While the expression of MMP-1, -2 , and -8 showed no significant relationships with intramuscular fat contents, MMP-1 and -2 showed significant negative correlations with the shearing force of the longissimus dorsi muscle in cattle. The expression of MMP-1 also showed a significant negative correlation with cooking loss and a positive correlation with water holding capacity. The expression levels of MMP-1 and -2 were usually higher in fat than in skeletal muscle tissue. The expression of MMP-8 was significantly higher in the mammary fat pad and the longissimus dorsi muscle than in all other tissues. This study indicates that the remodeling of the ECM has important effects both on the development of postnatal skeletal muscle and on meat quality.

Key words: Matrix metalloproteinases; Meat quality; Nanyang cattle; Muscle development 


\section{INTRODUCTION}

Matrix metalloproteinases (MMPs) are a family of enzymes that can selectively digest individual components of the extracellular matrix (ECM) in many tissues (Visse and Nagase, 2003). This regulates cell migration, differentiation, and regeneration in the processes of both normal physiological and pathological states (Zimowska et al., 2008; Wang et al., 2009). Twenty-five members of the MMP family have been identified and each MMP interacts in specific ways with certain elements of the ECM. MMP collagenases (MMP-1 and -8) have the ability to cleave interstitial collagen types I, II, and III, whereas MMP gelatinases (MMP-2) degrade denatured collagen types IV, VII, and X in many tissues (Chen and Li, 2009). MMPs are generally secreted in zymogen form through a conserved cysteine switch motif (PRCxxPD) in the pro-domain and are able to be extracellularly activated by several proteinases, such as plasmin and other activating MMPs. On the other hand, MMPs are also adjusted by four kinds of specific tissue inhibitors of metalloproteinases (TIMPs), which are synthesized by most types of connective tissue cells as well as by adipocyte and macrophages (Chun, 2012).

The skeletal muscle is the largest organ and has a character of great plasticity. In response to both physical and chemical signals, it allows the body to increase or decrease skeletal muscle size throughout adulthood. In adult mammals, an increase in muscle mass occurs primarily as a result of an increase in muscle fiber size (hypertrophy) rather than muscle fiber number (hyperplasia). The most vigorous muscle hypertrophy is accompanied by the remodeling of the ECM (Fry et al., 2014), in response to the increase of anabolic hormonal signaling (Zhang et al., 2013) or strength training. Many previous studies have shown that the ECM remodeling affects the muscle's normal function, its ability of hypertrophy, and the synthesis of intramuscular fat (IMF) (Moreno-Sánchez et al., 2010). Unfortunately, there is a paucity of objective information about the muscle ECM compared to other connective tissues of mesenchymal origin, such as tendon, ligament, bone, and cartilage. Therefore, in this study, the expression patterns of MMP-1, -2 , and -8 were explored during the development of longissimus dorsi muscle, and the relationships of MMP$1,-2$, and -8 expression levels with meat quality traits were analyzed in cattle. The expression of MMP-1, -2 , and -8 were also tested in four kinds of fat tissues and three kinds of skeletal muscle tissues. The results of this study may improve our understanding of the function of ECM remodeling in skeletal muscle development and its relationship with meat quality regulation.

\section{MATERIAL AND METHODS}

\section{Tissue collection, RNA isolation, and cDNA synthesis}

All experimental and surgical procedures were approved by the Biological Studies Animal Care and Use Committee of China. Nine pregnant cows were submitted to caesarean section to collect the fetuses at 135, 185, and 280 days gestation (three pregnant cows from each stage), and the longissimus dorsi muscles from each fetus were dissected and snap-frozen in liquid nitrogen for gene expression analysis. Postnatal longissimus dorsi muscle tissue samples (four animals at 3, 6, $12,18,24$, and 30 months of age) were collected in the experimental abattoir. Twenty-four Nanyang bulls aged 24 months were selected to investigate the correlation of meat quality with gene expression. The longissimus dorsi muscle was excised from each animal within 30 min post-mortem in an experimental abattoir. After dissection, samples were divided into two blocks: a big block was vacuum packaged for meat quality analysis and a small block was quickly frozen in liquid nitrogen 
and stored at $-80^{\circ} \mathrm{C}$ for gene expression analysis. The marbling fat samples were separated from longissimus dorsi muscles by ophthalmic instruments within 30 min post-mortem and the samples of mesenteric fat, mammary fat pad, subcutaneous fat, biceps femoris, and infraspinatus were separated from the bodies directly and frozen in liquid nitrogen immediately.

Total RNA was isolated from all samples using the RNAiso Plus kit (Takara, Dalian, China). RNA quality was determined by $1.2 \%$ agarose gel electrophoresis and absorbance at $260 \mathrm{~nm}$ in a NanoDrop ND-1000 ${ }^{\circledR}$ Spectrophotometer (Thermo Scientific, Wilmington, MA, USA). After DNase I (Takara) treatment, total RNA was reverse transcribed to cDNA using the PrimeScript ${ }^{\mathrm{TM}}$ RT reagent kit (Takara), following the manufacturer instructions.

\section{Quantitative real-time polymerase chain reaction (qRT-PCR) analysis}

qRT-PCR was performed on an $\mathrm{iQ}^{\mathrm{TM}}$ real-time PCR detection system (Bio-Rad, Hercules, CA, USA) using SYBR ${ }^{\circledR}$ Premix Ex Taq ${ }^{\mathrm{TM}}$ II kit (Takara). Thermal cycling consisted of an initial step at $95^{\circ} \mathrm{C}$ for $4 \mathrm{~min}$ followed by 42 cycles at $95^{\circ} \mathrm{C}$ for $30 \mathrm{~s}$, annealing for $20 \mathrm{~s}$ and extension/fluorescence acquisition at $72^{\circ} \mathrm{C}$ for $20 \mathrm{~s}$. The glyceraldehyde-3-phosphate dehydrogenase (GAPDH) gene was chosen as the reference gene for normalization of all data, because it was expressed more stably in muscle tissues. Each qRT-PCR (in $20 \mu \mathrm{L}$ ) contained $10 \mu \mathrm{L}$ SYBR $^{\circledR}$ Premix Ex Taq ${ }^{\mathrm{TM}}$ II, $0.7 \mu \mathrm{L}$ of each primer (Table 1 ), $1 \mu \mathrm{L}$ normalized template cDNA, and $7.6 \mu \mathrm{L}$ ultrapure water. The qRT-PCR measurements were performed in triplicate for each cDNA sample, and gene expression was quantified relative to GAPDH expression using the $2^{-\Delta \Delta C t}$ method (Livak and Schmittgen, 2001). Gene expression ratios were normalized to the GAPDH gene in the same sample.

Table 1. Information of primers used for real-time PCR analysis.

\begin{tabular}{|c|c|c|c|c|}
\hline $\begin{array}{l}\text { Gene } \\
\text { name }\end{array}$ & Template sequence & Primer sequence & $\begin{array}{l}\text { Annealing temperature } \\
\left({ }^{\circ} \mathrm{C}\right)\end{array}$ & $\begin{array}{l}\text { Product length } \\
\text { (bp) }\end{array}$ \\
\hline \multirow[t]{2}{*}{ MMP-1 } & \multirow[t]{2}{*}{ NM_174112.1 } & 5'-TGTTAGTCGCTCAGTCGTGTC-3' & \multirow[t]{2}{*}{56} & \multirow[t]{2}{*}{104} \\
\hline & & 5'-AACCCACTCCAGTATTCTTGC-3' & & \\
\hline \multirow[t]{2}{*}{ MMP-2 } & \multirow[t]{2}{*}{ NM_174745.2 } & 5'-GGACCAGAGCACCATTGAGAC-3' & \multirow[t]{2}{*}{60} & \multirow[t]{2}{*}{186} \\
\hline & & 5'-AGACTTGGAAGGCACGAGC-3' & & \\
\hline \multirow[t]{2}{*}{ MMP-8 } & \multirow[t]{2}{*}{ XM_005899520.1 } & 5'-AGAAAGCCTCGCTGTGG-3' & \multirow[t]{2}{*}{54} & \multirow[t]{2}{*}{135} \\
\hline & & 5'-TGCTTCCACATCCGTCTC-3' & & \\
\hline \multirow[t]{2}{*}{ GAPDH } & \multirow[t]{2}{*}{ NM_001034034.1 } & 5'-ATGCTGGTGCTGAGTATGTG-3' & \multirow[t]{2}{*}{54} & \multirow[t]{2}{*}{320} \\
\hline & & 5'-GAAGTTACGGCTATCTGTCG-3' & & \\
\hline
\end{tabular}

All primers were designed with the Premier 5.0 software and synthesized in Sangon Biotech (Shanghai, China) Co. Ltd.

\section{Meat quality trait measurements}

Meat tenderness measurements were conducted using a muscle tenderness device (CLM3, Tenovo, Beijing, China) with a Warner-Bratzler attachment. Prior to measurements of shear force, samples were cut into slices $25-30 \mathrm{~mm}$ thick, vacuum-packed, and heated in a water bath at $80^{\circ} \mathrm{C}$ to reach an inner temperature of $72^{\circ} \mathrm{C}$ and kept at the above temperature for $90 \mathrm{~min}$. Following heat treatment, samples were cooled to room temperature and cuboids were excised measuring $10 \times 10 \times 40 \mathrm{~mm}$, which were subsequently cut perpendicular to the muscle fibers.

To assess cooking loss, a 2.5 -cm slice of longissimus dorsi muscle vacuum-sealed in a polyethylene bag was frozen at $-20^{\circ} \mathrm{C}$. Samples were thawed at $4^{\circ} \mathrm{C}$ for $24 \mathrm{~h}$ and placed in a water bath at $80^{\circ} \mathrm{C}$ until an internal temperature of $70^{\circ} \mathrm{C}$ had been reached. The temperature was measured using a thermo recorder (TR-52, T\&D Corporation, Matsumoto, Japan) inserted into the center of the meat. The value of cooking loss was computed as [(original weight - weight after cooking) / original weight] $\mathrm{x} 100$. 
Water holding capacity was measured on fresh meat by a centrifugation method. Fresh meat $(0.5 \mathrm{~g})$ was placed in a centrifuge tube and cooked at $80^{\circ} \mathrm{C}$ for $20 \mathrm{~min}$, then centrifuged at 600 $g$ for $10 \mathrm{~min}$. Meat weights were measured before and after centrifugation. The isolated water content was calculated as (weight before centrifugation - weight after centrifugation) / (weight of fresh meat). The value of water holding capacity was calculated as [ $(70 \%$ fresh meat weight - weight of the isolated water) / (70\% fresh meat weight)] $\times 100$.

The IMF content of the longissimus dorsi muscles was determined by extraction with petroleum ether in a Soxhlet apparatus (VELP SER148, Usmate, Italy) and expressed as a percentage of muscle dry weight.

\section{Statistical analysis}

Gene expression at different stages or tissues was analyzed by one-way ANOVA followed by the Bonferroni test for pairwise comparison using the SPSS program Version 13.0 (SPSS, Chicago, IL, USA). The relationship of meat quality traits with gene expression levels was analyzed by the Pearson correlation at the significance level of 0.05 .

\section{RESULTS}

\section{Expression of MMP-1, -2 , and -8 during longissimus dorsi muscle development}

The expressions of MMP-1, -2 , and -8 showed a significant negative tendency before birth, especially the MMP-2, which was highest in 135-day fetuses and comparably much lower at postnatal stages. After birth, the expressions of MMP-1 and MMP-2 showed no significant change, while the MMP-8 had a significantly higher expression level at 24 months old compared to all other postnatal stages (Figure 1).
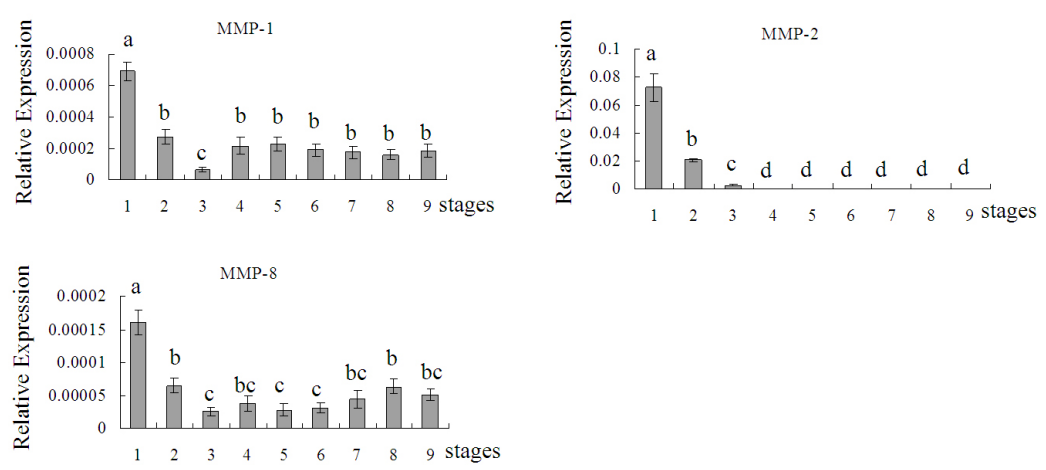

Figure 1. Expression of MMP-1, -2 , and -8 during the development of longissimus dorsi muscle in Nanyang cattle. Treatments shown using the same letter denote no significant difference $(P>0.05)$. Stages 1-9 denote: 1: pregnancy day $135 ; 2$ : pregnancy day $185 ; 3$ : pregnancy day 280; $4: 3$ months old; $5: 6$ months old; $6: 12$ months old; 7: 18 months old; 8: 24 months old; 9: 30 months old.

\section{Relationships of MMP-1, -2 , and -8 expression levels with meat quality}

The mean IMF content of longissimus dorsi muscle samples was $1.88 \pm 0.64 \%$, the maximal and minimal values were 3.37 and $0.84 \%$, respectively. The expression of MMP-1, -2 , and -8 
showed no significant relationships with intramuscular fat content in cattle. The mean shearing force of the longissimus dorsi muscle samples was $4.94 \pm 1.12 \mathrm{~kg} / \mathrm{cm}^{2}$, and the maximal and minimal shearing force values were 7.10 and $3.11 \mathrm{~kg} / \mathrm{cm}^{2}$, respectively. The Pearson correlation coefficients between shearing force of longissimus dorsi muscle and MMP-1 and MMP-2 expression levels were $-0.4326(P<0.05)$ and $-0.5420(P<0.01)$, respectively. This indicates that both MMP-1 and MMP-2 had significant negative effects on the shearing force of longissimus dorsi muscle in cattle (Table 2). The mean cooking loss of longissimus dorsi muscle samples was $24.86 \pm 3.28 \%$ (ranging from 20.1 to $29.5 \%$ ). The mean water holding capacity of longissimus dorsi muscle samples was $51.58 \pm 1.72 \%$, with the maximal and minimal cooking loss values being 53.6 and $49.2 \%$, respectively. The Pearson correlation coefficients of MMP-1 expression levels with cooking loss and water holding capacity of longissimus dorsi muscle were $-0.6822(P<0.01)$ and $0.7336(P<$ 0.01 ), respectively, which indicates that MMP-1 had significant effect on the cooking loss and water holding capacity of longissimus dorsi muscle in cattle (Table 2).

Table 2. Correlation coefficients of gene expression levels of MMP-1, -2 , and -8 with meat quality traits.

\begin{tabular}{l|c|c|c|c}
\hline Gene name & Intramuscular fat content & Shearing force & Cooking loss & Water holding capacity \\
\hline MMP-1 & 0.0243 & $-0.4326^{*}$ & $-0.6822^{\star *}$ & $0.7336^{\star *}$ \\
\hline MMP-2 & 0.3698 & $-0.5420^{* *}$ & -0.3152 & 0.0679 \\
\hline MMP-8 & 0.0300 & 0.0165 & 0.1759 & 0.3396 \\
\hline
\end{tabular}

${ }^{*}$ Correlation coefficient significant at $\mathrm{P} \leq 0.05$ and ${ }^{* *}$ significant at $\mathrm{P} \leq 0.01$.

\section{Expression of MMP-1, -2 , and -8 in muscle and fat tissues}

The expression levels of MMP-1, -2 , and -8 in four kinds of fat tissues and three kinds of skeletal muscle tissues are shown in Figure 2. The expression of MMP-1 was significantly higher in the mammary fat pad and subcutaneous fat than in skeletal muscle tissues (longissimus dorsi, biceps femoris, and infraspinatus) ( $\mathrm{P}<0.05)$. The expression of MMP-2 was also significantly higher in fat tissues (mesenteric fat, mammary fat pad, subcutaneous fat, and marbling fat) than in the skeletal muscle tissues (longissimus dorsi, biceps femoris, and infraspinatus) $(P<0.05)$. The expression of MMP-1 and MMP-2 differed significantly within the group of fat tissues, while no difference in expression was found within the group of muscle tissues. The expression of MMP-8 was significantly higher in the mammary fat pad and longissimus dorsi muscle compared to all other tissues $(P<0.05)$.
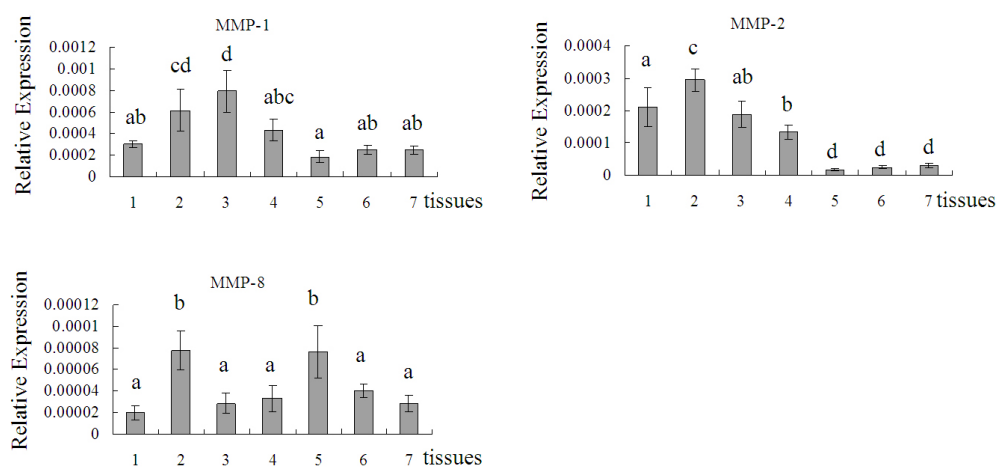

Figure 2. Expression of MMP-1, -2 , and -8 in different tissues. Treatments shown using the same letter denote no significant difference $(P>0.05)$. Tissues $1-7$ denote the following: 1 , mesenteric fat; 2 , mammary fat pad; 3 , subcutaneous fat; 4 , marbling fat; 5 , longissimus dorsi; 6 , biceps femoris; and 7 , infraspinatus. 


\section{DISCUSSION}

\section{Functions of MMP-1, -2 , and -8 in skeletal muscle hypertrophy}

ECM remodeling is important in maintaining homeostasis and muscle fiber functional integrity, both of which greatly affect the skeletal muscle development and hypertrophy (Carmeli et al., 2004). Previous studies have suggested that skeletal muscle hypertrophy is accompanied by the activation and contribution of satellite cells, which are released from the muscle fiber basement membrane and typically fuse to the preexisting muscle fibers to contribute to skeletal muscle hypertrophy (Yamada et al., 2006, 2008). Many studies have demonstrated that both the MMP-1 (Wang et al., 2009) and the MMP-2 (Zimowska et al., 2008) have important effects on the migration and differentiation of skeletal muscle satellite cells both in in vitro cultured muscle cells and in in vivo animal models, including mdx mice (an X-link dystrophic skeletal muscle mouse model). Deletion of the MMP-2 gene significantly decreased the extent of hypertrophy observed in MMP-2 knockout mice (Zhang et al., 2014) and an up-regulation of MMP-2 following a hypertrophic stimulus (Calve et al., 2012). This suggests that MMP-2 is a pertinent contributor to muscle hypertrophy. MMP-1 treatment directly stimulated the migration of target cells, by increasing the expression of the migration-related marker proteins $\mathrm{N}$-cadherin and $\beta$-catenin, as well as inducing the expression of MMP-2 and TIMP significantly in vitro (El Fahime et al., 2000). MMP levels were very low in normal muscle tissues, but the expression of MMP-1, -2 , and -9 could be increased in injured skeletal muscle (Kherif et al., 1999). Taken together, the reduced muscle hypertrophy resulting from decreasing the expression of MMP-2 was most likely due to reduced muscle ECM remodeling rather than a reduction in muscle protein synthesis. This suggests that MMP-2 plays a critical role in skeletal muscle hypertrophy by regulating muscle ECM remodeling. In the present study, the expression of MMP-1, -2 , and -8 in skeletal muscle showed a decreasing tendency in the fetus that indicates that the MMPs have important effects on the myogenesis in vivo. The expression of MMP-1 and -2 were not significantly different during the postnatal development stages of skeletal muscle in our study. This maybe due to the persistent and gentle hypertrophy occurring after birth.

\section{Relationships of MMP-1, -2 , and -8 with meat quality traits}

Collagen is the major component of skeletal muscle connective tissue, and its association with meat quality has been the target of numerous studies (Carmeli et al., 2004; Lambertz et al., 2014). The correlation coefficients between the tenderness rating and total collagen content in bovine longissimus dorsi muscle are usually found to be negative in animal experiments (Wheeler et al., 2002; Chriki et al., 2012). In this study, the expression of MMP-1 and -2 both showed significant negative correlations with shearing force, which is consistent with the theory that MMP-1 and -2 could promote the synthesis of collagen. The remodeling of the ECM has important effects on differentiation of preadipocytes and their ability to accumulate triglyceride lipid droplets (Chun, 2012), which indicates that the expression of MMPs could regulate the IMF by remodeling the ECM of preadipocytes and fibroblasts. Interestingly, MMP-1 has been reported as the most up-regulated MMP during the differentiation of cultivated adipocytes (Lessard et al., 2015). MMP-2-deficient mice were more resistant to high-fat diet-induced weight gain than littermate wild-type mice (Van Hul and Lijnen, 2008), which indicates that MMP-2 is essential to deposit lipids in the body. In this study, the correlation coefficient of MMP-2 expression levels with IMF in longissimus dorsi muscle samples was $0.3698(P=0.068)$. In our previous study, the expression of a disintegrin and metal- 
loproteinase with thrombospondin motifs 2 (ADAMTS2) was associated with increasing IMF in Nanyang cattle (Zhang XH, unpublished results). Treatment of 3T3-L1 adipocytes with Korean red ginseng extract inhibited lipid accumulation and reduced the expression of MMP-2 and -9 , which demonstrated that ginseng effectively inhibits adipogenesis and that this process may be mediated in part through the suppression of MMP-2 and -9 (Oh et al., 2012). The remodeling of the ECM in skeletal muscle could directly influence meat quality and IMF accumulation, and the mechanism needs to be further explored in the future.

Because the amount of collagen in muscle varies, it is reasonable to speculate that different muscle blocks have different meat quality traits and diverse MMP expression levels. Fibroblasts isolated from different muscle types had different in vitro growth potentials and MMP-2 expression levels (Archile-Contreras et al., 2010). The expression of MMP-2 was generally higher in fibroblasts cultured from semitendinosus than from sternomandibularis (Gillies and Lieber, 2011). In the present study, the expression of MMP-1 and -2 showed no significant difference within the group of muscle tissues, but the expression of MMP-8 was significantly higher in the longissimus dorsi muscle compared to in biceps femoris and infraspinatus. It was observed that the expression of MMP-1 and -2 was usually higher in fat than in muscle tissues. This indicates that the remodeling of the ECM occurs more quickly in adipocytes than in fibroblasts. A better understanding of the mechanism of ECM remodeling regulated by MMPs may lead to an increase in our understanding of the process of IMF accumulation and the breeding of excellent beef strains.

\section{CONCLUSIONS}

The expression of MMP-1, -2 , and -8 decreased significantly from 135 days of pregnancy to postnatal 30 months. The expression of MMP-1 and -2 showed significantly negative correlation coefficients with shearing force, while the expression of MMP-1 showed a significantly negative correlation with cooking loss and a positive correlation with water holding capacity of longissimus dorsi muscle in cattle. The expression levels of MMP-1 and -2 were typically higher in fat than in skeletal muscle tissues, and the expression of MMP-8 was significantly higher in the mammary fat pad and longissimus dorsi muscle than in all other tissues. This study indicated that the remodeling of ECM has important effects on both the development of postnatal skeletal muscle and meat quality.

\section{ACKNOWLEDGMENTS}

Research supported by the National Natural Science Foundation of China (\#31301941).

\section{REFERENCES}

Archile-Contreras AC, Mandell IB and Purslow PP (2010). Phenotypic differences in matrix metalloproteinase 2 activity between fibroblasts from 3 bovine muscles. J. Anim. Sci. 88: 4006-4015. http://dx.doi.org/10.2527/jas.2010-3060

Calve S, Isaac J, Gumucio JP and Mendias CL (2012). Hyaluronic acid, HAS1, and HAS2 are significantly upregulated during muscle hypertrophy. Am. J. Physiol. Cell Physiol. 303: C577-C588. http://dx.doi.org/10.1152/ajpcell.00057.2012

Carmeli E, Moas M, Reznick AZ and Coleman R (2004). Matrix metalloproteinases and skeletal muscle: a brief review. Muscle Nerve 29: 191-197. http://dx.doi.org/10.1002/mus.10529

Chen $X$ and Li Y (2009). Role of matrix metalloproteinases in skeletal muscle: migration, differentiation, regeneration and fibrosis. Cell Adhes. Migr. 3: 337-341. http://dx.doi.org/10.4161/cam.3.4.9338

Chriki S, Gardner GE, Jurie C, Picard B, et al. (2012). Cluster analysis application identifies muscle characteristics of importance for beef tenderness. BMC Biochem. 13: 29-39. http://dx.doi.org/10.1186/1471-2091-13-29

Chun TH (2012). Peri-adipocyte ECM remodeling in obesity and adipose tissue fibrosis. Adipocyte 1: 89-95. http://dx.doi. org/10.4161/adip.19752 
El Fahime E, Torrente Y, Caron NJ, Bresolin MD, et al. (2000). In vivo migration of transplanted myoblasts requires matrix metalloproteinase activity. Exp. Cell Res. 258: 279-287. http://dx.doi.org/10.1006/excr.2000.4962

Fry CS, Lee JD, Jackson JR, Kirby TJ, et al. (2014). Regulation of the muscle fiber microenvironment by activated satellite cells during hypertrophy. FASEB J. 28: 1654-1665. http://dx.doi.org/10.1096/fj.13-239426

Gillies AR and Lieber RL (2011). Structure and function of the skeletal muscle extracellular matrix. Muscle Nerve 44: $318-331$.

Kherif S, Lafuma C, Dehaupas M, Lachkar S, et al. (1999). Expression of matrix metalloproteinases 2 and 9 in regenerating skeletal muscle: a study in experimentally injured and mdx muscles. Dev. Biol. 205: 158-170. http://dx.doi.org/10.1006/ dbio.1998.9107

Lambertz C, Panprasert P, Holtz W, Moors E, et al. (2014). Carcass characteristics and meat quality of swamp buffaloes (Bubalus bubalis) fattened at different feeding intensities. Asian-australas. J. Anim. Sci. 27: 551-560. http://dx.doi. org/10.5713/ajas.2013.13555

Lessard J, Pelletier M, Biertho L, Biron S, et al. (2015). Characterization of dedifferentiating human mature adipocytes from the visceral and subcutaneous fat compartments: fibroblast-activation protein alpha and dipeptidyl peptidase 4 as major components of matrix remodeling. PLoS One 10: e0122065. http://dx.doi.org/10.1371/journal.pone.0122065

Livak KJ and Schmittgen TD (2001). Analysis of relative gene expression data using real-time quantitative PCR and the 2($\Delta \Delta \mathrm{C}(\mathrm{T}))$ Method. Methods 25: 402-408. http://dx.doi.org/10.1006/meth.2001.1262

Moreno-Sánchez N, Rueda J, Carabaño MJ, Reverter A, et al. (2010). Skeletal muscle specific genes networks in cattle. Funct. Integr. Genomics 10: 609-618. http://dx.doi.org/10.1007/s10142-010-0175-2

Oh J, Lee H, Park D, Ahn J, et al. (2012). Ginseng and its active components ginsenosides inhibit adipogenesis in 3T3L1 cells by regulating MMP-2 and MMP-9. Evid. Based Complement. Alternat. Med. 2012: 265023. http://dx.doi. org/10.1155/2012/265023

Van Hul M and Lijnen HR (2008). A functional role of gelatinase A in the development of nutritionally induced obesity in mice. J. Thromb. Haemost. 6: 1198-1206. http://dx.doi.org/10.1111/j.1538-7836.2008.02988.x

Visse R and Nagase H (2003). Matrix metalloproteinases and tissue inhibitors of metalloproteinases: structure, function, and biochemistry. Circ. Res. 92: 827-839. http://dx.doi.org/10.1161/01.RES.0000070112.80711.3D

Wang W, Pan H, Murray K, Jefferson BS, et al. (2009). Matrix metalloproteinase-1 promotes muscle cell migration and differentiation. Am. J. Pathol. 174: 541-549. http://dx.doi.org/10.2353/ajpath.2009.080509

Wheeler TL, Shackelford SD and Koohmaraie M (2002). Technical note: Sampling methodology for relating sarcomere length, collagen concentration, and the extent of postmortem proteolysis to beef and pork longissimus tenderness. J. Anim. Sci. 80: 982-987.

Yamada M, Tatsumi R, Kikuiri T, Okamoto S, et al. (2006). Matrix metalloproteinases are involved in mechanical stretchinduced activation of skeletal muscle satellite cells. Muscle Nerve 34: 313-319. http://dx.doi.org/10.1002/mus.20601

Yamada M, Sankoda Y, Tatsumi R, Mizunoya W, et al. (2008). Matrix metalloproteinase-2 mediates stretch-induced activation of skeletal muscle satellite cells in a nitric oxide-dependent manner. Int. J. Biochem. Cell Biol. 40: 2183-2191. http:// dx.doi.org/10.1016/j.biocel.2008.02.017

Zhang Q, Joshi SK, Lovett DH, Zhang B, et al. (2014). Matrix metalloproteinase-2 plays a critical role in overload induced skeletal muscle hypertrophy. Muscles Ligaments Tendons J. 4: 362-370.

Zhang XH, Qi YX, Pang YZ, Wang DD, et al. (2013). Expression of IGFs during postnatal development of Longissimus dorsi muscle and its relationship with meat quality traits in Nanyang cattle. Indian J. Anim. Sci. 83: 1009-1013.

Zimowska M, Brzoska E, Swierczynska M, Streminska W, et al. (2008). Distinct patterns of MMP-9 and MMP-2 activity in slow and fast twitch skeletal muscle regeneration in vivo. Int. J. Dev. Biol. 52: 307-314. http://dx.doi.org/10.1387/ijdb.072331mz 